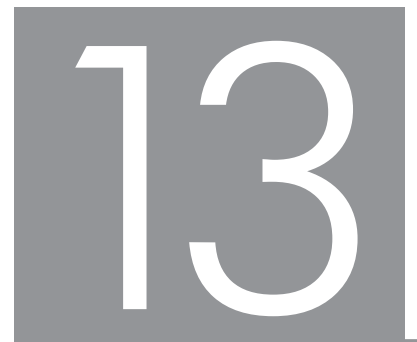

\title{
CREATING AN ONLINE COLLABORATIVE SPACE FOR KNOWLEDGE SHARING AMONG SERVICE LEARNING PARTICIPANTS
}

Elanie Myburgh

\section{ABSTRACT}

Communication is the foundation of a successful service learning project. All participants should have a voice and input in the project. A mutual platform enables participants to share knowledge, address issues and reflect on the experience. Creating an online communication platform to enhance collaboration and knowledge sharing among the participants in a recent study is the main focus of this chapter. Such a platform was created for a service learning project in which students from the University of the Free State engaged with a non-profit organisation in Heidedal, Bloemfontein. With this platform all the participants had more equal access to information and various forms of knowledge sharing happened simultaneously. Knowledge sharing on the platform created an inclusive environment for participants. A finding was that proper planning and time management on the part of the university staff member are crucial for the successful functioning of the platform. During the development phase reported in this chapter students and community members, in this instance mainly the manager of the non-profit organisation, reported feeling empowered because they had a more equal voice than in most service learning projects and they were able to share their views openly with all the participants. 


\section{INTRODUCTION}

A mutual, collaborative space for communication among participants in a community engagement project could contribute to creating inclusivity for all. In the context of community based research with its commitment to collaboration, shared power means that higher education institutions and community partners participate fully in shaping decisions about their work together. This is also true of service learning (SL) projects. Some communication problems in community partnerships are the by-product of bringing people from dramatically different professions and backgrounds together. Community participation in SL happens when the community is deliberately and actively involved not only in the execution of the services, but also in the conceptualisation, planning, implementation, monitoring and evaluation, maintenance and expansion of the services (Osman \& Petersen 2013:68). Collaboration includes not only the exchange of information, altering activities and sharing resources, but also enhancing the capacity of other partners for mutual benefit to achieve a common purpose (Andress 1993:55). Through participation and collaboration among the SL participants, a sustainable and long-term reciprocal relationship can be formed. Al-Khafaji and Morse (2006) state that SL serves as a compelling model in teaching sustainability, emphasising the cultivation of a sense of civic responsibility, engagement and commitment to community.

Currently, community engagement partners, and SL participants in particular, only have access to fragmented traditional online communication platforms such as email, text messages and other social networks. There is quite often a lack of knowledge sharing because of limited coordinated communication among the SL participants. Learners only flourish if education adapts successfully to the needs and demands of the age (Barnard 2005:24). Strand, Marullo, Cutforth, Stoecker and Donohue (2003:56) are of the opinion that web-based software, such as the mutual communication platform Blackboard, provides a useful forum for sharing information regarding the research or the SL project which includes written materials and meeting schedules. With the help of such a mutual platform, more communication, collaboration and knowledge sharing can take place. This means that if the non-profit organisation (NPO) representatives also have access to the platform, they will be able to communicate with the students and lecturers on a regular basis, and vice versa.

A mutual communication platform where all participants (NPO staff, students and higher education staff members) are able to communicate with one another on a daily basis would create a collaborative space for knowledge sharing. Working collaboratively on an SL project enhances the capacity to contribute for all the 
parties involved. Students learn how to conduct research, and both the students and academic staff members learn about the community and the practical challenges confronting people in disadvantaged positions in the society (Strand et al 2003:22). The participatory nature of many community-based research projects also gives the community members the opportunity to share their knowledge and to acquire new skills or develop others by working with academics and students.

Two theoretical frameworks are discussed in this chapter. The relationship continuum diagram (Bringle, Clayton \& Price 2009) and relevant literature explain the importance of good relationships between SL partners. The other framework is Salmon's online model (2000) that gives guidelines for successful interaction, knowledge sharing and communication on a mutual communication platform. Salmon's model is divided into five stages. The contention is that there could be a use for a mutual communication platform in community engagement projects as higher education staff members, NPO members and students involved in SL often feel there is not enough direct collaboration and communication among the SL participants. This can lead to a lack of the trust and respect among the participants that is crucial for relationship building. Through more effective communication and collaboration long-term relationships can be established that will form a firm foundation for collaborative activities.

The aim of this chapter is to report on the use of a mutual communication platform, more specifically the optimal use of a learning management system, to improve collaboration between NPO staff members, students and higher education staff members in an SL module/project. In this study the focus was on the first development phase of the module during which students communicated on the platform with the lecturer (the researcher) and NPO member (the NPO manager). The reason why only the NPO manager communicated on the platform was that the other NPO staff members did not have access to a computer or the internet.

The premise of this chapter is that enhanced communication and collaboration through a learning management system can lead to acquiring new skills and improved knowledge sharing among all the SL participants. Practical guidelines and tips are also shared to avoid pitfalls. If a mutual communication platform such as developed in this study is applied and used for knowledge sharing it can enable more effective collaboration between SL participants. Equal access to such a platform will enable SL participants to engage in more knowledge sharing. Online communication tools seem to best augment SL by providing a platform for tracking, sharing and assessing. 


\section{CHAPTER $13 \cdot$ MYBURGH}

\section{LITERATURE}

In exploring the literature related to creating a mutual collaborative space for knowledge sharing, various concepts are relevant. In this review of the literature, the mutual communication platform is described, followed by a discussion of the theoretical frameworks and models used. Finally, enhancing collaboration and knowledge sharing is discussed.

\subsection{Mutual communication platform}

While courseware was once primarily used for distance education, hybrid courses are gaining more popularity. Hybrid courses are those in which students and instructors meet regularly in a traditional classroom setting, but also include online components on a mutual communication platform (Jackson 2007:458). In a SL context a mutual communication platform, such as Blackboard, makes it increasingly possible for participants, which could include NPO members, other external partners, lecturers and students to collaborate through access to information and instructions. Collaboration between the campus administrator, academic staff, students and external participants is essential to the successful incorporation of information into online courses.

Setting up a successful and interactive platform takes planning and dedication, especially from the university staff member who coordinates the project. A mutual communication platform should not just be a dumping site for information; if wellstructured it affords academic staff members, external participants and students the opportunity to communicate, collaborate and share knowledge with one another. Mutual access to information on the platform can enhance the SL experience and knowledge sharing.

\subsection{Theoretical frameworks and models used}

Two theoretical frameworks are discussed, namely the relationship continuum and Salmon's five stage online model. These two models were used to enhance collaboration and knowledge sharing among SL participants.

\subsubsection{Relationship continuum model}

Bringle et al (2009:8) propose that practitioners in SL must be prepared to articulate a broad mission and particular goals to potential partners. They should know when relationships are mutually desirable (and know when and how to say "no" or "not now"). Furthermore, they engage in effective communication with diverse audiences, and have skilled staff in a centralised unit on campus to liaise between 


\section{ONLINE COLLABORATIVE SPACE FOR KNOWLEDGE SHARING AMONG SERVICE LEARNING PARTICIPANTS}

the various constituencies (Walshok 1999). When starting a relationship, two tasks exist for each member of the potential relationship (Wright 1999). The first task relates to deciding the type of relationship to follow (if any). The second task involves conveying interest (or lack thereof) to the other party. Bringle and Hatcher (2000) suggest that both these tasks will be facilitated in civic engagement by accurate selfawareness, communication and self-disclosure by all persons (Duck 1988, 1994). Figure 13.1 indicates how SL relationships can grow over time through interaction and communication.

\section{RELATIONSHIPS CONTINUUM}

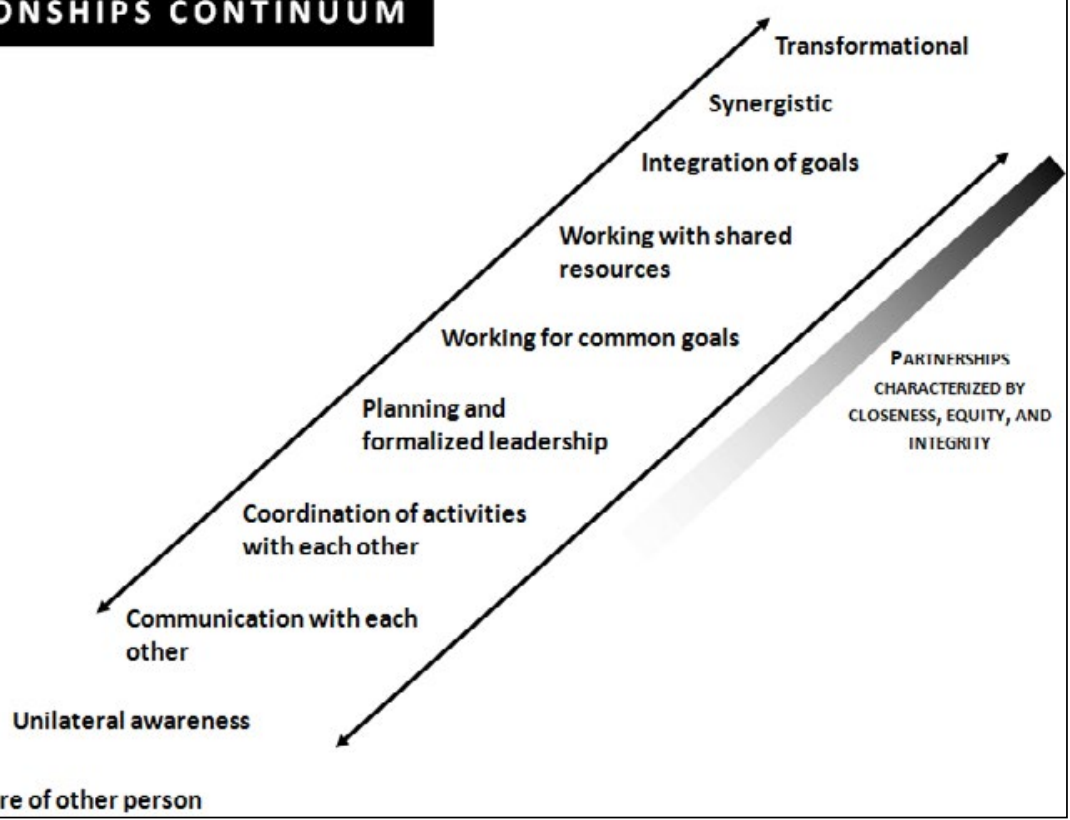

Unaware of other person

FIGURE 13.1 Different types or stages of relationships [Reproduced with kind permission from the authors. Source: Bringle et al 2009:4]

For the purpose of the investigation reported in this chapter, the above-mentioned relationship continuum provides a theoretical framework for tracking the progress of the relationships among the SL participants in the study. Indicators for enhancing collaboration that can be deduced from the continuum are reflected from the bottom upwards in the diagram from being unaware of the other to transformational. The arrows directed towards the 'transformational' end of the continuum represent the growth and direction of the relationship when proper communication and collaboration take place among the SL partners. 


\subsubsection{Salmon's five stage online learning model}

Salmon (2000:23) designed an online learning model that is divided into five stages. She maintains that online learning involves a series of stages, namely access and motivation, socialisation, information exchange, knowledge construction, and development. Her model illustrates the interplay between competence and affective factors such as growing confidence, motivation and group dynamics. The bottom line is that students are unlikely to be competent at learning in an online group until they are comfortable both with the tool and the group (see Figure 13.2).

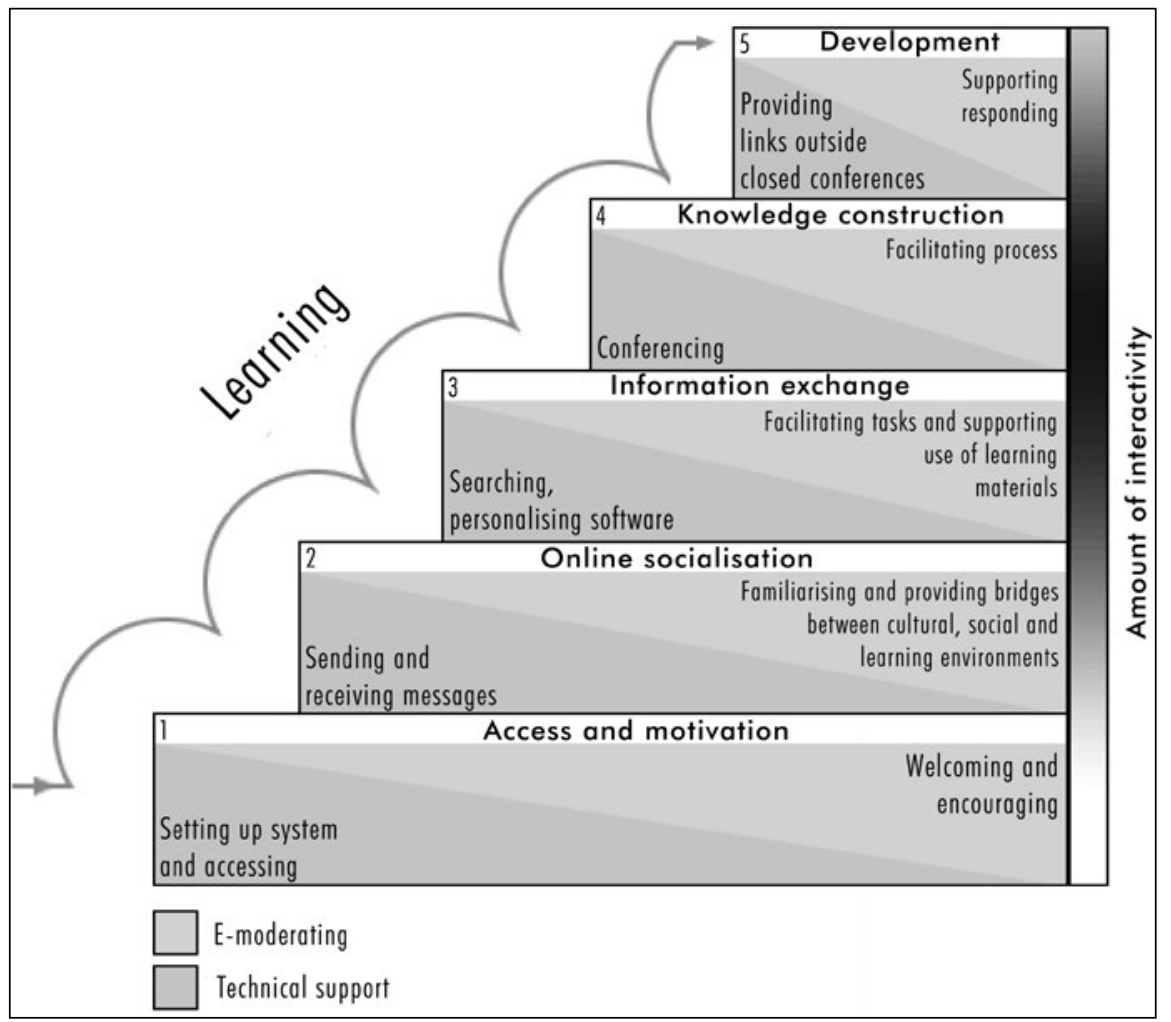

FIGURE 13.2 Salmon's five stage online learning model [Reproduced with kind permission from the author. Source: Salmon 2011:31]

Each stage of the Salmon model requires participants to master certain technical skills. Training should be given to all of the participants involved in order to explain how the five stages would work (shown at the bottom left of each step). Each stage calls for different e-moderating skills (shown at the top right of each step). The 'interactivity bar' on the right-hand side of the flight of steps suggests the intensity of interactivity that one can expect between the participants at each stage. 
During stage 1, participants interact only with one or two others. After stage 2, the number of other people with whom participants interact, as well as the frequency of interaction, gradually increases, although stage 5 often results in a return to more individual pursuits.

\section{Stage 1: Access and motivation}

For external role-players and students alike, being able to gain access to the mutual communication platform quickly and easily is a key issue at stage 1. The other key issue is being motivated to spend the time and effort. All the role-players should familiarise themselves with the new piece of software being used. Problems are often specific to a particular configuration of hardware, software and network access, or related to the loss of a password. Technical support is crucial at this stage. Stage 1 is when the moderator (lecturer or staff member) can expect to make first contact online with new students and also draw the external role-players into the discussion. Stage 1 is over when participants have posted their first messages (Salmon 2000:27). The following serves as an example of a very general question that works well as an icebreaker for this stage: Do you prefer sweet or salty snacks, and why?

\section{Stage 2: Online socialisation}

In stage 2 participants get used to being in the new online environment. Many of the benefits of a mutual communication platform in education and training flow from building an online community of people who feel they are working together at common tasks. However, establishing relationships is not inevitable, but depends on the participants' early experience with access to the system and integration into the virtual community. Mutual communication platforms have the potential to convey feelings and build relationships (Chenault 1998). A wide range of responses occurs. Some people are initially reluctant to commit themselves fully to public participation in conferencing, and should at first be encouraged to read and enjoy others' contributions to the content before taking the plunge and posting their own messages. Once participants feel at home in the online environment, and reasonably comfortable with the technology, they move on to contributing. The empathy developed through this stage of online interactions has proven to be an essential prerequisite for later course and knowledge related discussions (Preece 1999:63). Moderators should take the lead in promoting mutual respect amongst participants, defusing problems and counselling any apparent alienated or offended individuals. They should also try to help those participants with similar interests and needs to find each other. This stage has served its purpose and is over when participants start to share a little of themselves online (Salmon 2000:29). Questions that the students 


\section{CHAPTER 13 - MYBURGH}

had to answer during this stage include: What was your first impression today at the NPO? How easy or difficult is it for you to express yourself in writing on the learning management system? How did you feel emotionally after your first visit to the NPO?

It should be noted that the NPO manager could respond to what the students shared online and he was thus symbolically positioned at the same level as the lecturer. It was not expected of him to respond to questions put forward by the lecturer on the learning management system, and he could use his discretion about how and when he wished to join in the discussion.

\section{Stage 3: Information exchange}

A key characteristic of a mutual communication platform is that the system provides all participants with access to information in the same way. In stage 3 they start to appreciate the broad range of information available online. Information exchanges flow freely in messages, since the 'cost' of responding to a request for information is quite low. Participants require two kinds of interaction for learning to take place: interaction with the course content and interaction with people, namely moderators and other participants. At this stage, participants look to the moderator for guidance and direction on how to approach messages, and for encouragement to start using the most relevant content material. During this stage, motivation and enjoyment come from personal and experiential communication (Preece 1999). Participants must learn how to exchange information on the platform before they can move on to full-scale interaction in stage 4 (Salmon 2000:31).

At this point the participants had already become used to responding to one another's questions. Examples of questions that were used for students during this stage: Tell me how these past weeks of service learning have changed your outlook on life. It can be positive or negative. What perceptions did you have regarding service learning and working with the NPO? Have any of your perceptions changed? Please explain. Did you experience any challenges during this week? If so, please elaborate.

\section{Stage 4: Knowledge construction}

At this stage, participants begin to interact with each other in more exposed and participative ways. As participants communicate with one another, they engage in active learning, especially by widening their own viewpoints and appreciating different perspectives. Moderators have important roles to play at this stage. Feenberg (1989) coined the term 'weaving' to describe the flow of discussion and how it can be pulled together. The moderator undertakes the weaving; then pulls together the participants' contributions by, for example, collecting statements and relating them to concepts and theories discussed in the course. Moderators enable 
the development of ideas through discussion and collaboration (Salmon 2000:33). Questions that were posed during this stage include: Tell me about your experiences of working in a group. What skills do you think you have developed as a result of being part of this service learning project? What concerns do you have for the remainder of the project?

\section{Stage 5: Development}

During stage 5 participants become responsible for their own learning through computer mediated opportunities and need little support beyond that already available. Rather different skills come into play at this stage. These skills include critical thinking and the ability to challenge the 'givens'. During stage 5 moderators and participants are essentially using constructivist approaches to learning. Constructivism calls for participants to explore their own thinking and knowledge building process (Biggs 1995). When participants are learning through a new medium such as the mutual communication platform, their understanding of the processes of using the software and the experience of learning in new ways is being constructed too. It is therefore common at this stage for participants to reflect on and discuss how they are networking, and to evaluate the technology and its impact on their learning processes. When the module is set up on the mutual communication platform, the moderator must be prepared to answer difficult questions that relate to social, ethical and technical dimensions. Stage 5 will be completed when participants are commenting on and writing about each other's work (Salmon 2000:36). For the last stage of the model the lecturer can include reflective questions. Reflective types of questions enable the role players to think back on where they started, what they have achieved and how they have developed. Questions included: Tell me what you have learned during this service learning experience (academic, personal growth or service learning related). Tell me about any life lessons you have learned. Are there any changes that I as lecturer should consider for a similar service learning project for next year? Would you like to share anything else with your fellow students, the NPO manager and your lecturer?

\section{ENHANCING COLLABORATION AND KNOWLEDGE SHARING AMONG PARTICIPANTS}

Communication and collaboration functions on a mutual communication platform are more effective when the learner interacts with the technology, a coach/mentor, or other learners. In addition to the self-study mode, the platform should provide the opportunity for learner collaboration, coaching by experts in the subject matter, and the creation of learning communities. Communication and collaboration are facilitated 


\section{CHAPTER 13 - MYBURGH}

through asynchronous and synchronous communications, shared whiteboards and group spaces, and on-demand tutoring components (Robbins 2002).

Academic staff members need to appreciate the demands inherent in the collaborative process. Although individuals have their own expectations of group work, they need to define one another's actions so that they work together to create a shared practice. Out of necessity or convenience, individuals coordinate their activities to achieve common goals that, in time, guide future shared actions (Weick 1995). The relevant role-players' shared history and context (Selznick 1992) eventually provide the stability and predictability that are crucial for meaningful collaborative work to occur (Weick 1995). Aligning acts to develop a group's practice requires the 'mutual engagement' of members (Wenger 1998). In fact, participants' engagement in the learning process gives them a sense of belonging, an essential element of any professional learning community (Weick 1995). Wenger, McDermott and Snyder (2002) suggest that a learning community is a group of people who communicate on an ongoing basis to develop their knowledge of a common interest or passion by sharing individual resources and by engaging in critical dialogue. Although the learning generated from collaborative work depends largely on the ability of group members to establish a practice to achieve their common goals, such goals can be surprisingly difficult to identify (Weick 1979).

For purposes of the project that I am reporting on, a collaborative space was created on a mutual communication platform (Blackboard) where the pilot group ( $I$, the NPO manager and the students) shared knowledge, worked towards a common goal and coordinated activities relating to the SL project.

\section{RESEARCH METHODS}

I used a mixed method research approach within an action research framework in the study. There was a blend of qualitative and quantitative data collected in the phases throughout the research process (Creswell \& Plano Clark 2007:5; Ivankova, Creswell \& Plano Clark 2007:261-262). However, due to the inclusion of openended questions and the emphasis on reflective journals more qualitative than quantitative data were used. In Salmon's five stage model there are overlaps with aspects of action research (Salmon 2000:25).

A pre- and post-implementation student questionnaire comprising open and closed questions were used to collect data. Furthermore, online activities were structured on the mutual communication platform according to Salmon's five stage model and included reflective journals and discussions regarding the SL project. 
The pre- and post-implementation student questionnaires are compiled and distributed among students in all the SL modules at the University of the Free State (UFS). The pre-implementation questionnaire is used to determine the students' understanding and expectations of the SL module prior to its commencement. The post-implementation questionnaire, on the other hand, is used to gain insight into the students' experience and perspectives after completing the module in order to gauge students' development and to improve the module in future. These questionnaires were utilised for purposes of collecting data for the online SL project as well after relevant questions were added.

Both quantitative and qualitative data were collected by means of the pre- and postimplementation student questionnaires. Additional qualitative data were collected by means of the structured online activities that included the reflective journal entries that were posted on the mutual communication platform.

Purposeful, non-probability sampling was used as it involves selecting the most accessible individuals as respondents (Cohen, Manion \& Keith 2007:113). It was important that the target population included people with knowledge or first-hand experience of using a mutual communication platform, as this would enable the participants to provide valuable information that would improve understanding of the topic at hand. In this case, it was the 350 first year students enrolled at the Faculty of Economic and Management Sciences in 2012. A text message was sent to all these students to invite them to take part in the study voluntarily. In the end the sample group consisted of 20 undergraduate students between the ages of 18 and 25 years. The NPO manager and I were the final two participants of the sampling group.

The theoretical framework of the relationship continuum (Bringle et al 2009), Salmon's model of online learning (2000) and the UFS definition of service learning (UFS 2006) with indicators were used to conduct a deductive analysis. The qualitative data were analysed by reading and coding the online activities on the mutual communication platform. Main themes looked for in the online activities were increased communication, knowledge sharing and enhanced collaboration. By coding the text segments in the reflective journals, I identified themes that may be interrelated to form broad generalisations. Both pre- and post-questionnaires were uploaded onto the mutual communication platform and were only made available for one week each. SurveyMonkey software was used for the questionnaires and descriptive statistics. 


\section{CONTEXT OF THE STUDY}

Before the study could take place an appointment was made with the NPO manager to discuss the project and the use of a mutual communication platform. The NPO that was chosen for the study is situated in Heidedal in Bloemfontein. This NPO is involved in various service related activities in the community. As stated before, the students from the UFS were first year students in the age group 18 to 25 years. They were enrolled in the Faculty of Economic and Management Sciences. The faculty consists of five departments, namely accounting, economics, business management, public management and human resources.

Before the first meeting with the participants the activities were set up on the mutual communication platform. Salmon's five stage model was used to assist with setting up the correct questions and reflective activities.

The first meeting with the students and NPO members was on the same day that access and training were given on the mutual communication platform. The training took place in a computer lab and it was arranged beforehand for the participants to be enrolled for the specific module on the platform. After the training the students and NPO manager were able to log in to the platform and perform the online activities.

The week after the training the students and I visited the NPO. The NPO manager presented the various projects to the students and he suggested that they divide into smaller groups and set up a plan of action. The students divided themselves into smaller groups according to the department in which they were registered. The first group was called the 'Marketing Ladies', the second group the 'Accountants', the third group the 'Telephone Ladies', and the last group the 'Library Chicks'. Each group had a chance to speak to the manager and other staff members at the NPO. When they left the NPO, each group had a clear plan of action. Each of the groups had specific tasks they had to complete. The 'Marketing Ladies' assisted the NPO with designing and drawing up of marketing material for the ten year celebration of the NPO. The 'Library Chicks' trained the staff in using a computer system for lending out books. They also reorganised the whole library according to a colour code system and books were categorised according to the alphabet. The 'Accountants' assisted the NPO staff members in drawing up a budget for the ten year celebration function and showed them how to price the items for the bakery. The 'Telephone Ladies' drew up a letter with the help of the NPO manager to approach cell phone companies to set up a community telephone at the NPO premises in order for community members to make use of it and pay a minimum fee for using the phone. 
After every visit to the NPO, the students, the NPO manager and I were afforded the opportunity to complete the online activities and communicate via the platform.

\section{RESULTS}

First, the student responses to the pre- and the post-implementation student questionnaire were compared to establish to what extent the mutual communication platform enhanced collaboration among participants from a student perspective. Next, the data obtained from the online activities completed by the participants on the platform were analysed. The NPO manager, the students and I had access to the reflective journals and contributed on the platform.

The following broad indicators posed by Bringle et al (2009) were utilised to evaluate the relationship and the quality of collaboration: closeness, equity and integrity. In accordance with triangulation design principles, I endeavoured to join the two data sets (quantitative and qualitative results) in order to form a more holistic picture with regard to creating a mutual collaborative space for knowledge sharing among SL participants.

\subsection{Results obtained from the pre-implementation student questionnaire}

The results from the pre-implementation student questionnaire showed that $80 \%$ of the respondents wanted to communicate with the NPO manager on the mutual communication platform before their first visit to the NPO site. The reasons for communication before their visit ranged from "getting a better understanding of what is expected" from them to "wanting to discover the role of the NPO manager in the community". They also wanted to be more prepared for the interaction in general.

\subsection{Results obtained from the post-implementation questionnaire}

The respondents had to answer specific questions regarding the use of the mutual communication platform. In response to one question, 93\% of the respondents answered that the platform helped them to communicate better with the NPO manager. Communication was enhanced because it was easily accessible to all the participants. The service learning definition (UFS 2006) stipulates that a module requires a collaborative partnership context that enhances mutual, reciprocal teaching and learning among all members of the partnership. The evidence thus indicates that the collaboration among the participants, and thus within the partnership, has been enhanced through more effective, regular communication on the platform. 


\subsection{Results obtained from the activities on the mutual communication platform}

Salmon's (2000) online model and the UFS definition of service learning (2006) created the analytical framework for the study. Every week some items of the relationship continuum of Bringle et al (2009) were achieved, and the participants progressed to new stages of Salmon's online model each week. Improved levels of closeness, equity and integrity were achieved and lifelong learning took place. Knowledge sharing among the participants (students, NPO manager and myself as lecturer) took place every time an online activity was carried out.

Stage 1 of Salmon's model - access and motivation - was reached before the first reflective journal entry because all participants of the pilot study had to log in to the platform during training. A trial question and answer session on the platform took place during the training. This familiarised participants with the setup.

Participants were asked about their concerns regarding the use of the mutual communication platform and whether they foresaw any problems. The theme that stood out was that the participants looked forward to being able to communicate and collaborate with other participants at any given time. No challenges were mentioned regarding the use of the platform, but rather that the pressure with their studies and schedules that could interfere with the project. A comment from one of the participants was:

The use of the platform will help us improve our computer skills and ease communication among all.

The relationship indicator - communication with each other - stood out in responses to the reflective journal question.

The aim of the second week's reflective journal was to reach stage 2 of Salmon's model, namely online socialisation. Participants commented on journal entries by fellow students, the NPO manager and me. Stage 2 was successfully reached.

The reflective questions the participants had to answer were whether they found it difficult to express themselves on the platform. A participant commented:

I am a very shy person but the platform gives me the courage to speak my mind without being criticised like in a classroom setting.

After the second journal entry an enhanced sense of closeness among all the participants was evident. The visit to the NPO was reported as being a humbling experience for the students. Reciprocal teaching took place because the students also started to learn from the NPO members. Indicators of the relationship continuum of Bringle et al (2009) that were achieved were working for common goals, planning and formalising leadership. 
During the third journal entry the third stage of Salmon's model - information and exchange - came to the fore. Students, the NPO manager and I had to share and give information on the platform. The questions asked were on an emotional level and this helped to address certain indicators of the relationship continuum. Equity and closeness among the participants grew with each week's activities.

One participant wrote:

I thought that I was not going to play any significant role in this project, that I did not have what it takes to contribute something of value. These feelings decreased as we approached the second week because my fellow students, [the NPO manager] ${ }^{1}$ and [the researcher/lecturer] ${ }^{2}$ encouraged me and made me feel part of something bigger when they commented on my postings.

With regard to knowledge construction in the fourth stage of Salmon's model, the participants had to facilitate processes, for example plan to reach weekly goals. The processes they facilitated were done in their groups. Each group had a specific goal in mind and the journals helped them to understand and realise the role that each one had in the group. In terms of the relationship continuum the following indicators were achieved: coordination of activities with each other, planning and formalising leadership, integration of goals and synergism. All of the abovementioned indicators enhanced the closeness and relationship building among the participants. A student wrote:

We communicate a lot on the mutual communication platform and it helps our group to stay focused.

During week 5 of the pilot study, I did not comment on any journal entries. The main reason for this was that I wanted to establish whether the platform really enhanced the communication among the other participants. By not communicating with the NPO manager and students, I could clearly establish whether the relationship continuum and Salmon's framework worked during the pilot study. At the beginning of the pilot study, the NPO manager and students were dependent on the feedback and communication from me, but as the weeks passed they became close to their group members and the NPO manager, mainly because it was so much easier to communicate on the platform where they also had equal access to information.

There were mixed reactions and feedback from the participants, as shown by these two responses:

1 The students used the first name of the NPO manager in the data set.

2 The students used the first name of the researcher/lecturer in the data set. 


\section{CHAPTER $13 \cdot$ MYBURGH}

I was okay when [the researcher/lecturer] did not respond to my comments because my group members and [the NPO manager] did. I did not feel lost because I had other people to help me.

Every time I logged on to [the] platform I was looking for a reply from [the researcher/lecturer]. When I saw she was not responding to our questions I felt sad because her feedback and comments motivated me each week to become better.

The last stage of Salmon's online model stipulates that development should take place along with learning and interactivity. During the course of six weeks the NPO manager, the students and I commented on and replied to journal entries. Development of skills, enhancement of communication, and interactivity are just a few of the indicators that improved over the period. A question regarding the use of the platform was asked to all the participants to determine the success of the platform use.

The theme that emerged most from the reflective question was that participants could communicate and share ideas and knowledge on a regular basis without having to meet in person. It was a convenient and quick way for participants to communicate with other participants.

\section{DISCUSSION}

The discussion of results comprises consideration of reflective journal activities and communication among participants.

\subsection{Reflective journal activities on the mutual communication platform}

The reflective journal that was completed each week allowed the students, the NPO manager and me to discuss certain topics in a shared space. We all had access to all of the journals and could comment on a post. All of the role-players mentioned in their last reflective journal entry that it was much easier to communicate on the mutual communication platform because one could log in and post a new discussion or reply to a post. The group's response towards the mutual communication platform was positive. It saved them much time because they did not have to arrange a meeting that would suit everyone, and since they could use the mutual communication platform, communication did not cost them a cent.

It helped in the terms of communication with group members, [the researcher/ lecturer] and [the NPO manager], to let the others know any important information and the platform made it more convenient for us to communicate without having to meet up. 
It is clear from the above comment that the platform was a convenient communication tool because it was easily accessible. The reflective journals on the mutual communication platform not only helped the students and NPO manager to communicate more regularly, but truly enhanced their SL experience. Participants could put their words and feelings in writing.

Figure 13.3 shows a screenshot of one week's reflective journal questions.

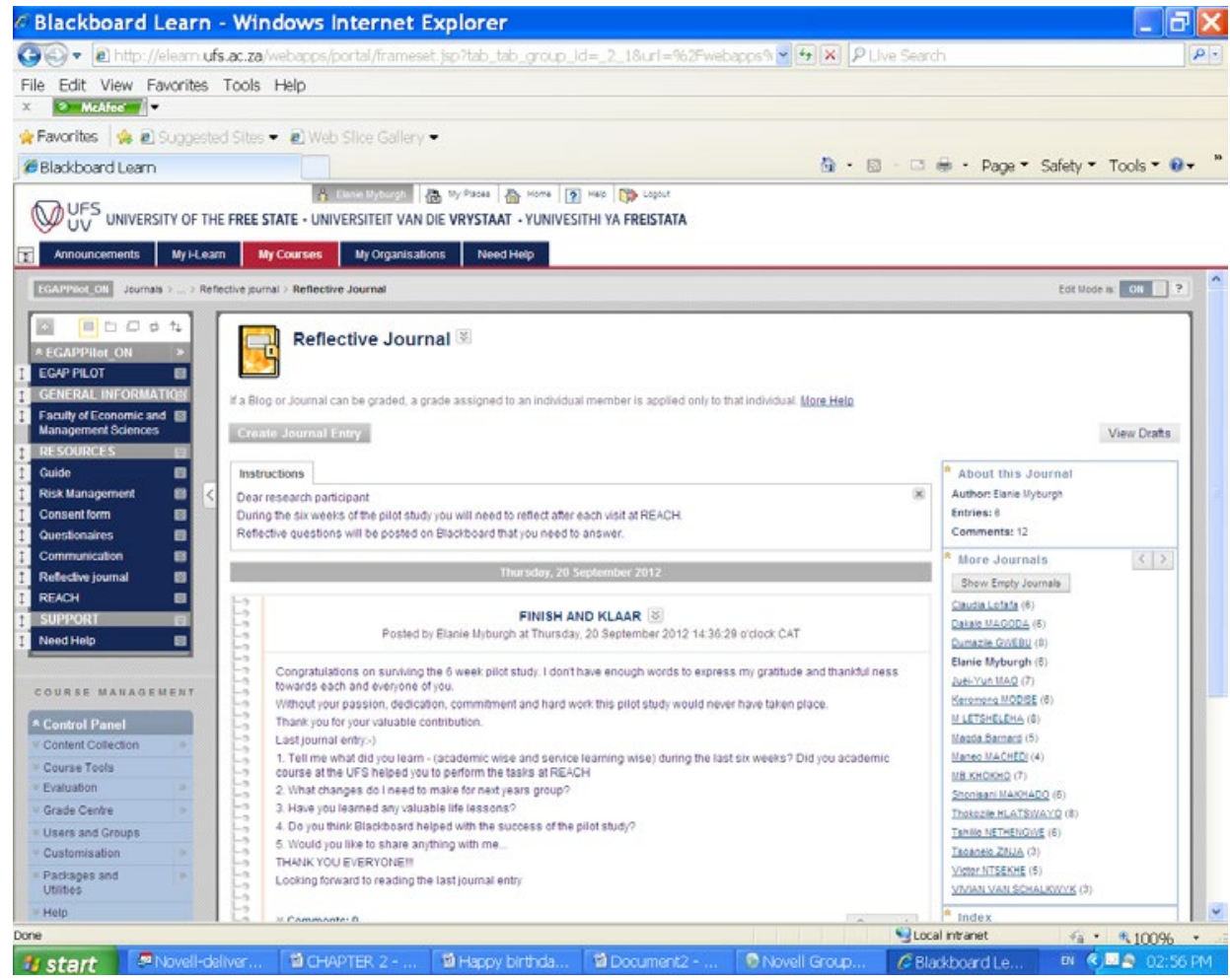

FIGURE 13.3 Reflective journal screenshot

\subsection{Communication among participants}

Communication among the students, the NPO manager and me occurred on a daily basis during the pilot study period. The students valued the fact that the NPO manager took time out of his busy schedule to reply to some of their questions or concerns. Some students were shy, but felt that the mutual communication platform gave them a safe space in which to share their ideas. Once the shy students got a positive response from fellow students or the NPO manager they had more courage to share their ideas during the Friday meetings when everyone met. Not only did 


\section{CHAPTER 13 - MYBURGH}

the platform help with communication, but it gave all the participants an equal chance to contribute to their group and common goal. The indicators 'closeness' and 'equity' had been successfully enhanced.

I benefited a lot from the journal entries. In addition to that all the reflections from the members gave awareness of weighing the benefits of the project and concerns/request from the participants. By knowing each other better and our interest via the platform, this kept everyone in peace and harmony.

Equal access to information on the platform put all the participants on equal footing and this enabled the participants to feel more at ease with each other. Feedback from the NPO manager and me encouraged the students to communicate more frequently. The NPO manager has participated in SL projects for more than ten years but during this project it was the first time that he could 'speak' to the students and academic staff directly without having to wait for the weekly visit to answer questions or raise concerns about projects. In the past he also did not have direct access to students and their views. He found communication through a mutual platform both intriguing and enabling in terms of working towards reciprocity in the SL module.

Although the students, the NPO manager and I had access to a computer, only a few of the students own a computer. Most of them went to the library or computer lab to log in to the platform. Therefore I suggest that the NPO members and students should download the mutual communication platform application on their mobile phones for future use. By downloading the application on a smart phone they will be able to log in, comment or write journal entries while driving in a taxi, watching television or while being at home.

The screenshot in Figure 13.4 shows how the mutual communication platform can be utilised not only for reflective journals but also to communicate important information and share documents with all the role-players. 


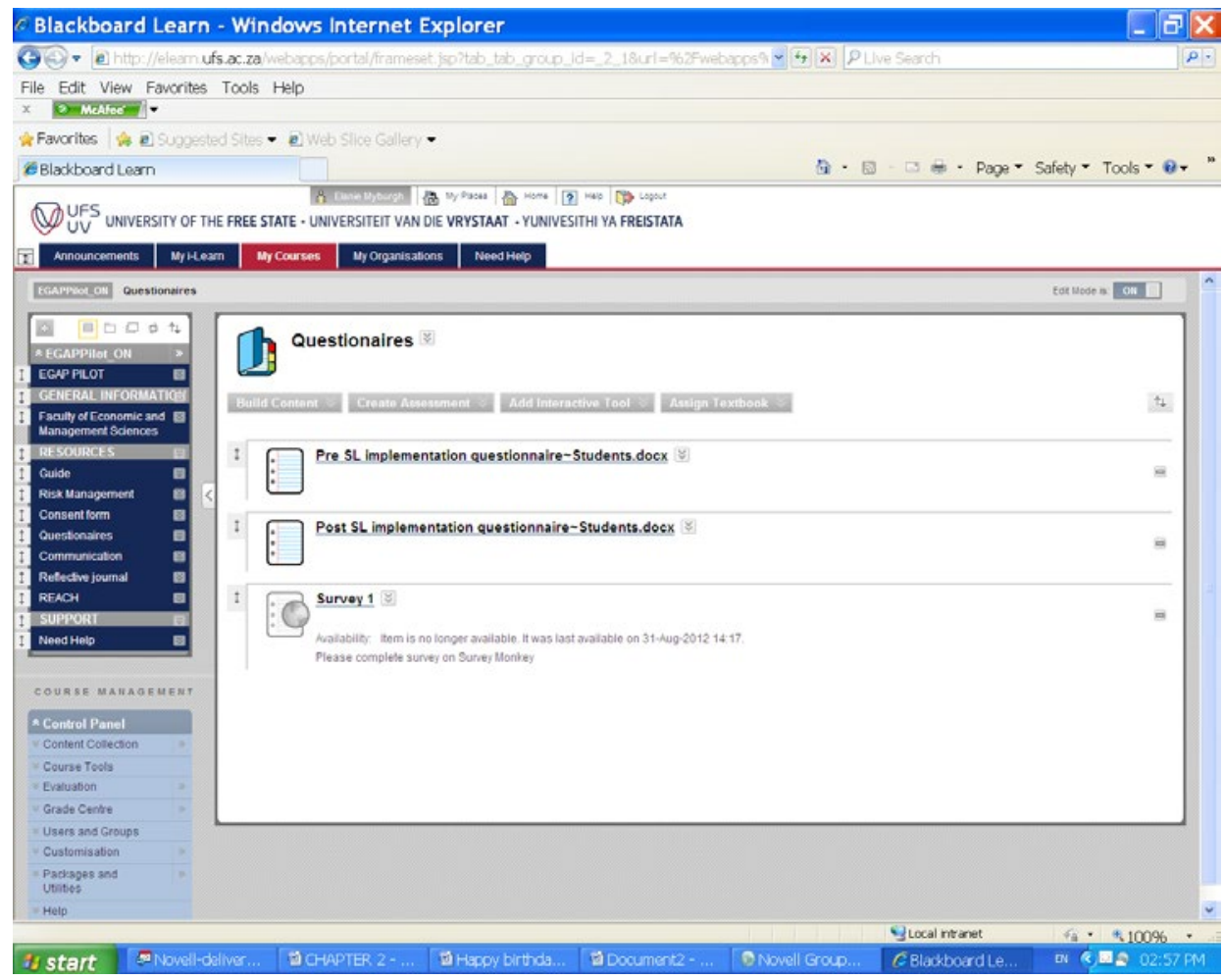

FIGURE 13.4 Role-player communication and sharing

\section{CONCLUSION}

Service learning projects can only be a success if there is proper communication. The collaborative space available on a mutual online communication platform enabled service learning participants to communicate openly and honestly. Knowledge sharing could happen throughout because the participants could reflect and share experiences. The mutual communication platform created a safe environment in which the participants could communicate and this assisted with relationship building and development of trust among all the participants. The use of such a platform enhances the service learning experience because the role-players have access to information about the NPO, the community, the project and the literature utilised for the project. In addition, sharing of information on the platform can assist higher education institutions and NPO partners in setting up a database for record keeping and for follow-up projects.

Just as participants learn how to communicate with each other across sociocultural divides, they also learn how to recognise and work around the challenges (Strand et 
al 2003:36). Communicating on the platform can help them to identify challenges quickly, to get input from all the participants to address the challenges and to move forward with minimum delay.

For the successful development of a service learning module that makes use of a mutual online communication platform for collaboration purposes among academic staff members, students and NPO staff in future, good planning, time management and proper communication on the platform should be encouraged. The coordinating staff member should evaluate all comments, discussions or blogs on the platform to ensure that the content being discussed is relevant and helpful to the service learning project. Proper training should be given at the beginning of the module for the students and NPO staff members to familiarise them with the use of the platform. University staff members should have guidelines and procedures in place for ethical issues and problems such as racist remarks, swearing and bullying.

University staff members who coordinate such projects should continuously aim to add and improve the use of technology and mutual communication platforms in service learning modules in order to keep communication channels open among all the role-players. This study provided evidence, on a small scale, of the positive effect that a mutual, online communication platform can have on collaboration and knowledge sharing among service learning participants.

\section{REFERENCES}

Al-Khafaii K \& Morse M. 2006. Learning sustainable design through service. International Journal for Service Learning Engineering, 1(1):1-10.

Andress S. 1993. Working together for youth: A practical guide for individuals and groups. Minneapolis, MN: Lutheran Brotherhood.

Barnard G. 2005. Why e-learning affects us all. British Journal of Administrative Management, $46(12): 24-25$.

Biggs JB. 1995. Assessing for learning: Some dimensions underlying new approaches to educational assessment. Alberta Journal of Educational Research, 41:1-18.

Bringle RG, Clayton PH \& Price MF. 2009. Partnerships in service learning and civic engagement. Partnerships: A Journal of Service Learning \& Civic Engagement, 1 (1):4-12.

Bringle RG \& Hatcher JA. 2000. Institutionalization of service-learning in higher education. The Journal of Higher Education, 71:273-289.

Chenault BG. 1998. Developing personal and emotional relationships via computer-mediated communications. Computer-Mediated Communication Magazine, May. [Retrieved January $2014]$ http://www.december.com/cmc/mag/1998/may/chenault.html

Cohen L, Manion L \& Keith M. 2007. Research methods in education. 6th Edition. New York: Routledge. 


\section{ONLINE COLLABORATIVE SPACE FOR KNOWLEDGE SHARING AMONG SERVICE LEARNING PARTICIPANTS}

Creswell JW \& Plano Clark VL. 2007. Designing and conducting mixed methods research. Thousand Oaks, CA: Sage Publications.

Duck SW. 1988. Relating to others. Chicago: Dorsey.

Duck SW. 1994. Meaningful relationships. Thousand Oaks, CA: Sage.

Feenberg A. 1989. The written world. In: R Mason \& AR Kaye (eds). Mindweave communication, computers, and distance education. Oxford: Pergamon Press. 22-40.

Ivankova NV, Creswell JW \& Plano Clark VLP. 2007. Foundations and approaches to mixed methods research. In: K Maree (ed). First steps in research. Pretoria: Van Schaik.

Jackson J. 2007. Mutuality, engagement, and agency: Negotiating identity on stays abroad. Paper presented at 17th International Conference on Pragmatics and Language Learning. University of Hawaii at Mãnoa, 25-28 March.

Osman R \& Petersen N. 2013. Service learning in South Africa. Cape Town: Oxford University Press Southern Africa.

Preece J. 1999. Empathic communities: Balancing emotional and factual communication. Interacting with Computers, 12:63-77.

Robbins S.R. 2002. The Evolution of the Learning Content Management System. Learning Circuits. [Retrieved January 2014] http://www.learningcircuits.org/2002/apr2002/ robbins.html

Salmon G. 2011 E-moderating: the key to teaching and learning online. (3rd Edition). London and New York: Routledge. 31

Selznick P. 1992. The moral commonwealth: Social theory and the promise of community. Berkeley, CA: University of California Press

Strand K, Marullo S, Cutforth N, Stoecker R \& Donohue P. 2003. Community-based research and higher education: Principles and practices. San Francisco: Jossey-Bass.

SurveyMonkey. [Retrieved January 2014] http://www.surveymonkey.com

UFS (University of the Free State). 2006. Community Service Policy / Samelewingsdiensbeleid. [Retrieved January 2014] http://www.ufs.ac.za/servicelearning

Walshok ML. 1999. Strategies for building the infrastructure that supports the engaged campus. In: RG. Bringle, R Games \& EA Malloy (eds). Colleges and universities as citizens. Needham Heights, MA: Allyn \& Bacon. 74-95.

Weick KE. 1979. The social psychology of organizing. Reading, MA: Addison-Wesley.

Weick KE. 1995. Sensemaking in organizations. London: Sage Publications.

Wenger E. 1998. Communities of practice: Learning, meaning, and identity. Cambridge: Cambridge University Press.

Wenger E, McDermott R \& Snyder W. 2002. Cultivating communities of practice: A guide to managing knowledge. Boston, MA: Harvard Business School Press.

Wright DE. 1999. Personal relationships. Mountain View, CA: Mayfield. 